\title{
VEREDAS DE ENFRENTE: MARTINFIERRISMO, ULTRAÍSMO, MODERNISMO
}

POR

\author{
RAÚL ANTELO \\ Universidad de Santa Catarina, Brasil
}

\section{FORMA, ANTIFORMA}

Montevideo es una vereda de enfrente de Buenos Aires, es un lindísimo barrio que está un poco a trasmano, que se ha ido a veranear. ${ }^{1}$

La frase de Borges, mezcla de boutade y lugar común para la pretensión cosmopolita del porteño, da cuenta, con todo, de la peculiar situación de la capital uruguaya en esos años del veinte: reliquia fantástica, marca del pasado, Montevideo es "el Buenos Aires que tuvimos", eco de "calles con luz de patio", pero es también una puerta falsa en el tiempo, por donde se anuncia lo que vendrá. No en vano, anota Macedonio Fernández, que es en Montevideo "donde se divisa pronto lo irregular nuestro, como nosotros desde aquí observamos lo inestable de Europa" ${ }^{3}$ Ciudad bisagra, metáfora móvil, Montevideo es también el proyecto inconcluso de modernidad que la literatura argentina no quiere ver.

Dos vanguardistas, Borges y Le Corbusier, tuvieron, al menos, un punto común: ambos apreciaban las azoteas montevideanas. No la mansarda de importación reciente sino la azotea criolla, ensalzada por los viajeros. ${ }^{4}$ De ese

${ }^{1}$ Jorge Luis Borges, "Vicente Rossi. Cosas de negros, Córdoba, 1926”. Valoraciones 10 (La Plata, agosto 1926), 39.

${ }^{2}$ Borges, "Montevideo" en Martin Fierro, 8-9 agosto-6 setiembre 1924. Incluido después en Luna de enfrente (1925).

${ }^{3}$ Macedonio Fernández, "El zapallo que se hizo cosmos" en Papeles de Recienvenido. Continuación de la nada. Prol. Ramón G. de la Serna (Buenos Aires: Losada, 1944), 266.

4 Setenta años antes de Le Corbusier, un médico francés, Amedée Moure, autor de un Tratado de geografia elementar, física, historica, eclesiástica e poltitica do Imperio do Brasil, escritoen colaboración con V.A. Malte Brun, publica en París, en la Revue Espagnole Portugaise, Brésilienne et Hispano-américaine (1857), curiosas observaciones sobre las azoteas montevideanas:

En Montevideo las casas tienen un aire de fiesta. Blanqueados sus frentes con cal, su interior da testimonio de la coquetería y el lujo de sus moradores. Si el gusto francés ha presidido este interior, hay en el exterior algo americano que no carece de gracia y de alegria. Asi, en vez de 
gusto despojado debe provenir la solución de Corbu para Montevideo: un rascamar, osado proyecto complementario del rascacielos porteñoy del rascatierra de São Paulo. Nunca el ornamental Palacio Salvo: ça ne marche plus.

Empujado a América por su amigo y paisano Blaise Cendrars, al visitar Montevideo, los primeros días de noviembre del 29, Le Corbusier fulminó el adefesio de Palantini:

si no viniera de ver el insoportable bodrio que se llama Pasaje Barolo, fealdad máxima de la Avenida de Mayo y de Buenos Aires, me hubiera sorprendido más aún todo lo que exhibe de abyecto este incréble mamarracho que Uds. tienen que aguantar como una irremediable calamidad pública.

Los hermanos Guillot Muñoz, cronistas de la visita a Montevideo, recuerdan que el arquitecto Jeanneret coincidió con Jean Aubry, para quien el Palacio Salvo era "l'accouplement monstreux de l'américain et de l'italien; c'est de la patisserie italienne". Le Corbusier, no obstante, fue más lejos diciendo que:

al ver la salchichería que sirve de decoración a la fachada de este innoble edificio, las molduras carnavalescas que trepan hasta la torre y las roscas adiposas que cuelgan de la planta baja y del primer piso, encuentro que el Palacio Salvo es algo bufo, c'est rigolo. ${ }^{5}$

Sin embargo, en esa destrucción de lo bello armonioso estaba precisamente la fuerza del símbolo. Del Palacio Salvo se podría decir lo que el mismo Le Corbusier de la torre Eiffel: la torre mató a París pero ahora París es la torre.

nuestros angulosos tejados de pizarra casi negros, cubre cada casa una terraza plana, belvedere con balaustrada de piedra alrededor. Es alli adonde sube cada mañana la bella montevideana para saludar a una amiga, a un vecino, o para enviar sobre la punta de un abanico un suspiro hacia un corazón que, más lejos, sobre otra terraza, lo recibe y parece complacerse en los vaporosos pensamientos que le trae. Es también allí adonde, después de la cena, va la familia a descansar de los trabajos de la jornada. Todas estas terrazas están por la tarde coronadas de flores humanas. Se fuma, se toma el mate, se mira lo que pasa en el vecindario y por la ciudad; es también alli donde se recibe la visita de un amigo, al mismo tiempo que se lo presenta al vecino. Un observatorio o mirador, de algunos metros de elevación, permitelanzar una ojeada escruta dora sobre toda la ciudad mientras la guitarra acompaña al cantor, en medio de las conversaciones de la sociedad reunida en la terraza. iNo se dirfa que sobre ese observatorio hay un sabio atento, largavista en mano, disputando al cielo sus más ocultos misterios?

Amedée Moure, Montevideo y Buenos Aires a mediados del siglo XIX. Trad., prólogo y notas José M. Mariluz Urquijo (Buenos Aires: Perrot, 1957), 30-1.

"Gervasio y Alvaro Guillot Muñoz, "Le Corbusier en Montevideo". La Cruz del Sur, 27, (Montevideo, enero-febrero, 1930). Invitado por Victoria Ocampo y Alfredo González Garaño, intimo amigo de Ricardo Güiraldes, Le Corbusier pronuncia diez conferencias en Buenos Aires, la primera quincena de octubre del 29. Enseguida, el 566 de noviembre, Le Corbusier viaja a Montevideo y Brasil en el Giulio Cesare. En la ciudad uruguaya propone un rascacielos en forma de $T$, semi-enterrado en el cerro, por sobre el cual pasa una autopista que termina en una barranca de 80 metros sobre el nivel del río. En São 
De Seurat a Delaunay, pasando por Huidobro y Maiacovsky, Cocteau y Milhaud, todos iconizan lo moderno en la torre. Monumento babélico de las mezclas, la torre, el rascacielos, marcan cruces inseminadores, nuevas ondas. No en vano, por ejemplo, Luis Cardoza y Aragón identifica Mazda(de su libro Maelstrom) con la mujer ciudad, asexuada, mujer-vidrio. Mazda es eiffélica porque lanza su red de arrastre para pescar París. ${ }^{6}$ Un año más tarde, en 1927, los radio-escuchas de los horizontes se abren a las ondas que otra torre, en otra banda, irradia. En ese año, Juvenal Ortiz Saralegui publica, en Montevideo, Palacio Salvo.

¿Qué es Palacio Salvo? Caracterizado en la cubierta de Héctor Fernández y González, como libro de "poemas", matiza, sin embargo, ese rótulo al definir el poema título - anticipado ya por el segundo número de la revista Izquierdacomo un "antipoema", categoria que a su vez anuncia la de un próximo volumen, Antiluna, casi una luna de enfrente. Hay aqur una deliberada elección: no tanto la azotea o el patio borgeanos, que evocan espacios de abolengo ya pasado, sino el rascacielos futuro. A lo sumo, un Salvo funcionalizado y eficiente, depurado de ornamentos pero símbolo inequivoco de la metrópoli. No el barrio expurgado de Borges sino el centro o el "barrio lunfardo y malón;/jugando al fútbol la calle/ mientras la acera milonga/pasa meneando un foxtrot". No el bandoneón de Ipuche, que acrisola "la zandunga violenta del Africa,/y las cosas más gauchas de la vida". En su lugar, el fox. Tampoco el campo sino el barrio de entrevero, donde se cruzan el tango y el blues; el tango, que Sergio Piñero intenta salvar y que Borges adecenta porque "el tango no es campero: es porteño. Su patria son las esquinas rosaditas de los suburbios, no el campo; su ambiente, El Bajo; el sauce llorón de las orillas, nunca el ombún.$^{7}$ Es, por otra parte, la distancia

Paulo, a donde viaja invitado por Paulo Prado, culminará el desarrollo de las propuestas de Buenos Aires y Montevideo: una autopista elevada en cruz. Ocioso decir que esa visita histórica de Le Corbusier da un impulso fundamental a la arquitectura modernista brasileña. Para más datos ver Mário de Andrade, "Le Corbusier", Diário Nacional (São Paulo, 21 noviembre 1929), la revista de Graca Aranha, Movimento Brasileiro 12 (Rio de Janeiro, 1929); Pietro Maria Bardi, Lembrança de Le Corbusier. Atenas, Italia, Brasil. Prefácio Alexandre Eulálio. (São Paulo: Nobel, 1984), y, finalmente, Fernando Pérez Oyarzun, Le Corbusier y Sur América. Precisiones en torno a un viaje, unos proyectos y algo más. (Santiago de Chile: Pontificia Universidad Catolica de Chile. Ediciones de la Escuela de Arquitectura, 1987).

- Luis Cardoza y Aragon, Maelstrom. Pref. Ramón Gómez de la Serna (Paris: Excelsior, 1926). La obra fue reseñada por A.M.F. (Alfredo Mario Ferreiro) en el número 19-20 de La Cruz del Sur (Montevideo, enero-febrero 1928).

${ }^{7}$ Jorge Luis Borges, "Ascendencias del tango", Martín Fierro 37 (Buenos Aires, 20 enero 1927), reproducido en El idioma de los argentinos (Buenos Aires: Gleizer, 1928), 121. Aunque Borges acepta que la milonga es el origen del tango, no cree, en cambio, que la milonga sea sólo montevideana, de donde entra en desacuerdo con la teoría orientalista del tango de Vicente Rossi. En "Apunte férvido sobre las tres vidas de la milonga", publicado en Martin Fierro el 15 de agosto del 27 y también incluido en El idioma de los argentinos, Borges puntualiza que el bandoneon cobarde y el tango sin salida no son 
que va, en el caso del modernismo brasileño, de la ciudad internacionalizada de Mário de Andrade, rosa entre tinieblas, "grande boca de mil dentes" a la recuperación del pasado provinciano en Manuel Bandeira. No es casual, si lo pensamos desde esta perspectiva, que Bandeira se identifique (jtodavía en 1941!) con el patio de Borges. ${ }^{8}$ En resumen, al ser antipatio, Saralegui es propuerto, propuesta por la apertura y por la mezcla. ¿De dónde viene su definición anti-poemática? Seguramente del peruano Enrique Bustamante y Ballivián, que en enero de ese mismo año publicaba en Buenos Aires su colección de Antipoemas (Sociedad de Publicaciones El Inca, 1927), volumen que debe haber sido del conocimiento de Ortiz Saralegui, ya que Bustamante y Ballivián desempeñaba funciones diplomáticas en Montevideo por esa época, antes del traslado a Río de Janeiro, de tan provechosas consecuencias para la difusión de los modernistas brasileños en el Perú. Pero Palacio Salvo no sólo debe a un poeta peruano su categoría genérica, de poesía existencial, sino que explicita en su portada inequívoco reconocimiento al concepto que César Vallejo entonces propone: palacio Salvo es "poesía nueva".

En efecto, el libro de Ortiz Saralegui transcribe el final de la crónica de Vallejo, que, con ese título, fue publicada en París en julio del año anterior y en que su autor discriminaba la poesía nueva, a base de palabras nuevas (pedante,

porteños: hay que sobrellevarlos. Como diría Piñero en su artículo "Salvemos el tango", de la misma revista (5 agosto 1925), la inmigración, que todo lo invade, le quitó autoridad al imperio del facón y del taco alto. Por eso la salvación, para Borges, está en rescatar el alma varona de la milonga en el tango primitivo, anterior a la inmigración.

${ }^{8}$ Jorge L. Borges, "Um pátio". Trad. Manuel Bandeira. Pensamento da América, supl. $\operatorname{de} A$ Manhā (Rio de Janeiro, 30 setiembre 1941). No es sólo en este caso que se nota el gusto conservador de Bandeira. Un rápido examen en el catálogo de su biblioteca arroja este perfil convencional: las Obras Completas de Rodó y los ensayos de Américo Castro y Raúl M. Bustamente sobre Ariel; las Poestas Completas de Delmira Agustini y Herrera yReissig; el Proceso intelectual del Uruguay deZum Felde, y su Indice de la poesta uruguaya contemporánea; el Teatro de Florencio Sánchez, el Tabaré de Zorrilla, "El Terruño" de Carlos Reyles y obras colectivas como la Antología rioplatense de Alvaro Yunque y Humberto Zarrilli, y el Panorama de la poesta gauchesca y nativista del Uruguay de S. García. No es mucho más variado el espectro argentino: a la Antologia de Fernández Moreno se suman los Poemas de Borges y los últimos libros de Girondo, poeta a quien Bandeira conoció en el 43, cuando con Norah Lange visitó Rio de Janeiro. En esa ocasión (A Manhã, 7 agosto 1943) confiesa su admiración por Calcomanias, "que Ribeiro Couto e eu líamos e relíamos con delícia há quase vinte anos na tranquilidade provinciana daRrua do Curvelo, em Santa Teresa". No hay duda de que Bandeira era, en los años 20, lector de los martinfierristas. El mismo Ribeiro Couto le agradece el envio de un número de la revista en carta fechada en Pouso Alto el 26 de setiembre del 27, ocasión en que también le recomienda mandar las Poestas a Nicolás Olivari: "Mande urgente! Ele que pediu!" (Recuerdese que Olivari citara, entre otros, a Bandeira y Ribeiro Couto, poeta de la penumbra, en el artículo que escribe sobre la moderna literatura brasileña en Martín Fierro 23) (Buenos Aires, 25 setiembre 1925). 
complicada, barroca), de la poesía nueva a base de nueva sensibilidad, simple y humana, sin atraer forzosamente la atención sobre su fachada moderna pero definida como revolucionaria por sus relaciones con el mundo. Esta es, por lo que se desprende, la intención de Saralegui, al escribir, y la de Vallejo al leer Palacio Salvo. La revista Vanguardia (a.1, $\mathrm{n}^{\circ}$ 1, Montevideo, setiembre 1928), editada por Juan Carlos Welker y el mismo Saralegui, transcribe una carta del autor de Trilce en que leemos:

Su libro me ha impresionado de veras. Ha sido una preciosa sorpresa la poesia, nueva y fuerte de su libro. Nueva y fuerte. Los dos valores juntos. Las grandes obras polarizan su mérito en estos dos extremos de belleza y nada más. El resto es mero adjetivo. Decir a Ud. que su libro es esto, aquello y lo de más allá, me parecería circunstancializarlo, juzgándolo con rasero churrigueresco de decadencia china. La fuerza y la frescura, por el contrario, constituyen indicación de simplicidad, índice de substracto. Ambas cualidades fundamentales obran muy por encima y muy al fondo de todas las demás.

Yapoyado en el concepto de Cocteau de un secreto profesional vanguardista (contra el que escribiría para Variedades en mayo del 27), prosigue:

Ud. es de los que crean cosas nobles, humanas, naturales, eternas. Sin adornos ni revocacos. Sin fórmulas ni trucos. Sin manera ni secreto profesional, sin simbolismo ni virtuosismo. Todo directo, elfptico,justo. Fraternizo hondamente con su estética, mi querido compañero.

En pocas palabras, a Vallejo no le caben dudas de que Ortiz Saralegui, habiendo conseguido escribir poemas sin adornos ni revocacos, alcanzó también la poesía nueva y el anti-Salvo, sin esas roscas adiposas ni las molduras carnavalescas tan condenadas por Le Corbusier. Sin revocacos, sin estuco, sin revoque y sin revocar lo perentorio, sin buscar lo viejo-feo, lo revo-caco, Ortiz Saralegui plasma, como observóJulioJ. Casal, lo natural y fluido. ${ }^{9}$ En ese mismo diapasón suena la carta de Mário de Andrade, transcripta en la misma ocasión por Vanguardia. El autor de Pauliceia Desvairada le confiesa a Saralegui que

9 "Entre nuestros jóvenes escritores, Juvenal Ortiz Saralegui es uno de los pocos que no se han contentado con saber andar bajo la gracia de la nueva sensibilidad. Después de Linea del alba, libro que sirvió de pretexto para que el ingenio anduviera bella y ágilmente por el verso nos da el milagro de Flor cerrada y esta ya lograda y fervorosa ofrenda de Las dos niñas. Sale el poeta con firmes redes y anda por ríos clásicos y así en sus sonetos luce el primor y la destreza de los maestros castellanos". Y tras detectar algo del perfil barroco de Gongora y del sobrio equilibrio de Garcilaso, el director de Alfar concluye: "con este libro llega el poeta al culminamiento de su oficio, sirviéndose de sus ventajas para que el verso sea más natural y fluido". Julio C. Casal, Juvenal Ortiz Saralegui: Las dos niñas (Buenos Aires: Editorial Losada, 1943) en Sur 117, Buenos Aires, julio 1944, 96-8. 
Mi esperanza de siempre es encontrar poetas bien de ahora bien desprovistos de ciertos exclusivismos también de ahora. Las preocupaciones artísticas de nuestro tiempo son tan intelectuales y los temperamentos surgen tan individuales que cada artista se especializa en un rincón de la técnica lírica, siéndonos raro encontrar una figura bien totalizada y vasta. Me parece que Ud. consigue eso tal vez por esa sensualidad general por todo lo que hay en el mundo tan claramente manifestada en Palacio Salvo. El agua que es sensual, toca todo y no esconde nada. Todo queda a través de ella con un temblor intenso de vida. Ud. tiene esa sensibilidad del agua y por eso Palacio Salvo es notable.

Nueva para Vallejo, natural para Mário de Andrade, fluida para ambos, la poesía de Ortiz Saralegui insinúa un ultrásmo comedido, es decir un nuevo realismo. A pesar de su apariencia, ese muchacho casi rubio, de regular estatura, gordo y trajeado de gris se presenta ante sus pares como contrario a fórmulas. Alfredo Mario Ferreiro, tal vez la voz más fuerte del grupo ultraísta uruguayo, por eso lo acepta, justificando la deformación poética del autor de Palacio Salvo como premisa cierta de desautomatización de una percepción rutinizada y que busca naturalizarse como nueva convención.

Juvenal Ortiz Saralegui canta la vida tal comoél la vé. Hay unos cuantos poetas que ya cantan la vida como ellos la ven. Frente a este número de cantores sinceros está el grupito - itan ridículo! - de los que tienen fórmula. Es decir, de los que se han ido pasando unos a otros una recetita, una especie de vidrio de colorinches al través del cual ven la vida. Y la ven igualmente idiota; la ven con los mismos consonantes. (El alma siempre en calma; si hay dolor tiene que haber amor; si pasan dos o tres siglos, enseguida aparecen los vestiglos; si va de sombrilla, será amarilla, irá por la orilla, se aposentará en una silla con ... esterilla). ${ }^{10}$

En esa reseña Ferreiro expone, como diría Borges, un síntoma de inquisición y un garabato de hoguera. Su ejecución de los poetas-fórmula recuerda el sacrificio ritual de tres típicos atributos novecentistas, que el autor de Inquisiciones emprende en su primer libro: inefable, misterio y azul, vocablo éste:

que apicardo de gandules, frondoso de abedules y a veces impedido de baúles se arrellana por octosílabas y sonetos en los sitiales donde antaño pontificaron los rojos con su arrabal de abrojos, rastrojos y demás asperezas consabidas. ${ }^{11}$

Como diría el mismo Borges en otra ocasión, la rima tiene un pecado original, su ambiente de engaño.

${ }^{10}$ Alfredo Mario Ferreiro, "Palacio Salvo. Poemas". La Cruz del Sur 22, 33 (Montevideo, 1929). El libro de Saralegui fue publicado en Montevideo por A. Barreiro y Ramos en 1927. ${ }^{11}$ Jorge Luis Borges Inquisiciones (Buenos Aires: Proa, 1925), 157. 
Más allá de lo que hoy nos parece rutinaria normalidad, en el caso de Palacio Salvo, como en el de gran parte de la vanguardia latinoamericana, es necesario observar el proyecto global, vale decir, los cortes que la obra produce en las estructuras estéticas y sociales, los cambios introducidos en la sensibilidad y en la sociabilidad. Visto de esa perspectiva el poemario de Ortiz Saralegui podría ser interpretado como un ensayo de apropiación del espacio urbano modernizado. Saralegui se da una ciudad y un marco de referencias que sabe, de antemano, perecibles porque el futurismo ya le había mostrado la gran lección de modernidad: la obsolecencia de lo simbólico. O en palabras de Sant'Elia: las casas durarán menos que nosotros y cada generación deberá construir su ciudad. ${ }^{12}$

Si la poesía de Saralegui suena nueva y natural, corriente, es porque, a su modo, sueña realizar una premisa de lo moderno: acelerar los flujos. Podría entonces aplicársele la observación de Paolo Portoghesi en relación al lenguaje arquitectónico del mismo Sant'Elia: en el diseño de la nueva ciudad encontramos mucho más que una reinterpretación del cul to barroco por lo espectacular. Nos deparamos, al contrario, frente al culto futurista del movimiento mecánico:

la città a più livelli, prima di essere soluzione razionale di problemi funzionali, e contemplazione di una macchina complessa in cui il traffico assume il ruolo che ha l'acqua in una fontana. ${ }^{13}$

Siendo antibarroca, esa idea no deja de ser paradojalmente antimoderna. Mejor dicho: inscribe en las obras - y Palacio Salvo no es, claro está, ni el único ni el mejor ejemplo- una contradicción entre lo posfuncional y el design, entendido como valor estético y anticipo alegórico de una supuesta ciudad futura. Así, en el ultraísmo es fácil detectar una tensión paralela entre elementos vaciados de decorativismo modernista y apuestas emergentemente constructivistas. En su alarde de ruptura voluntarista, el ultraísmo exaspera el puntillismo hasta fragmentarlo, transformándolo en estilización del impresionismo. Figari, Ipuche.

La lectura de Alfredo Ferreiro es, pues, coherente con su programa de superación de los determinismos. Como la naturaleza es imperfecta, se espera del hombre moderno una corrección que viene bajo la forma de la aceleración de los cambios e intercambios. Las palabras en libertad, la analogía en desvarío cristalizada en las greguerías y el simultaneísmo retórico corren parejos con esa frase eufórica y bohemia de incipiente industrialización. La única higiene del

12 Antonio Sant'Elia, "La arquitectura futurista (11 julio 1914)" en Filippo Tommaso Marinetti, Manifiestos y textos futuristas (Barcelona: Ed. del Cotal, 1978), 225.

${ }^{13}$ Paolo Portoguesi, "Il linguaggio di Sant'Elia" en Controspazio 4-5 (abril-maio 1971), 30; Aldo Colonetti, "L'Architettura futurista come ultra-architettura",Alfabeta. Suplemento número 84 (Milán, mayo 1986), 63. 
mundo es, en rigor de verdad, la guerra industrial. De ahí que los elogios al Palacio Salvo de Saralegui sean la manifestación de una estructura de sentimiento compartida por el autor de los poemas con olor a nafta. ${ }^{14}$ Gervasio Guillot Muñoz observa certeramente esas correspondencias entre El hombre que se comió un autobús y su entorno cuando, en el "Paragolpes delantero y faro piloto", anota que:

la intimidad lírica de este poeta se toca con la ferocidad automática de la urbe y crea, por disposición milagrera, una zona única por donde corre, desatado, un autobús y por donde suben el entendimiento estético, la ligereza mental y la curva aceleradora.

No es en ello nada singular. El libro de Ferreiro espejea y expande el primer poema de Palacio Salvo, "Ómnibus", que concluye, al modo futurista, invocando ese:

\author{
¡Mitin mecánico \\ con las bandas de música de los motores \\ y las carrocerías que aplauden \\ y las palancas \\ voces de la velocidad!
}

Claro que antes aún de Saralegui, $-\mathrm{y}$ sólo para citar otro ultraísta del Plata- Leopoldo Marechal ya había definido el ómnibus como coctelera que servía un copetín democrático. A la movilidad de las clases en el marco de la ciudad, se suma entonces la movilidad caleidoscópica de los espacios entrevistos por las ventanillas, "que no acaban nunca de elegir los paisajes" ${ }^{15}$ lo que provoca

\footnotetext{
14 Los textos poéticos de Ortiz Salaregui se complementan con los del mismo Ferreiro. Es el caso de la greguería que abre su "Poema del rascacielos de Salvo" (El hombre que se comio un autobús, poemas con olor a nafta. Montevideo, La Cruz del Sur, 1927): "El rascacielos es una jirafa de cemento armado/con la piel manchada de ventanas", que puede aún leerse en paralelo con los versos del argentino Girondo o del brasileño Menotti de Picchia: "O Pão de Açúcar é um pescador filósofo/de costas voltadas para o mar" ("Bahia da Guanabara", publicado originalmente en el tercer número de la revista Estética, de Rio de Janeiro, abril-junio 1925, e incluido ese mismo año en el volumen Chuva de Pedra.

15 "Breve ensayo sobre el 6́mnibus" Martin Fierro 20 (5 agosto 1925). Si el ómnibus es una cajita de sorpresas que actualiza una tradición que escinde producción y propiedad ("el 'chauffeur' es un Caronte con camiseta de punto"; "Dante hubiera creado el círculo del ómnibus para castigar el pecado de trabajar") hay otra caja de sorpresa, otra tradición, que busca integrar ambos términos por la via de un ocio primitivo y estridente: la jazz-band. En otro número de la misma revista, (27-28, 10 mayo 1926) Marechal publica un poema con ese título en que se lee: “ $j J a z z$ Band! Caja de sorpresas, cuyo muñeco versicolor golpea las narices incautas de la seriedad". Se trata, en verdad, de su interpretación de un orteguiano tema de nuestro tiempo, ya que el jazz es visto como "gritería de niños o de
} 
una consecuente movilidad de la mirada. La modernidad es movimiento, velocidad. La modernidad, para Ferreiro como para Saralegui, es la absolutización del tiempo y del espacio bajo la forma de una eterna velocidad omnipresente. La modernidad, en fin, para los ultraístas como, antes de ellos, para los futuristas:

C'est reporter à une unique et volontaire praxis de vie toutes les formes possibles d'existence et d'action. Entraîner en une "religion de la volonté extériorisé" $\rightarrow$ selon la définition du méme Marinetti- tout principe de la réalité en un dessin précis et martelant. L'art comme vie, l'art comme totalité, l'art comme mission."

Esta lectura vitalista y voluntarista del arte dista, claro está, de ser unánime. Combatida por los pasatistas, tampoco era aceptada por algunos de los escritores de vanguardia. Huidobro, como se sabe, le recrimina a Marinetti un abobado infantilismo, que prefiere el automóvil a la pagana desnudez de la mujer. Jorge Luis Borges, comentando El hombre que se comió un autobús, insiste en el mismo tópico:

Alfredo Mario Ferreiro es el único futurista que he conocido. No es, como el orador itálico Marinetti, un declamador de las máquinas ni un dominado por su envión o su rapidez; es un hombre que se alegra de que haya máquinas. También que haya viento y potros y vidas. Es decir, la realidad le da gusto. ${ }^{17}$

No se piense, sin embargo, que Borges despreciase el trabajo de Ferreiro. Para el crítico de Inquisiciones sólo los "playos escritores malévolos" merecían el silencio. Dedicarle un examen "filoso y desbastado" es prueba elocuente de que sus versos viven, "sólo nos dan un minuto de placer, pero nos lo dan". ${ }^{18}$ Véase más bien el desdén borgeano por la calle vanguardista, volcada de rondón en los

salvajes, para hombres, niños o salvajes, porque s6lo en los niños y los bárbaros pueden resucitar las bocas muertas de la alegria”. Recordemos, por último, que en ese mismo año, la revista Valoraciones de La Plata había publicado un dibujo de Marechal, también titulado "Jazz-Band", que reaparecerá como viñeta de Leopoldo Marechal [sic] en el volumen del futurista italiano Anton Giulio Bragaglia, Jazz Band (Milán, Corbaccio, 1929).

16 Ester Coen, "Les futuristes et le moderne" en Les cahiers du Musée National d'Art Moderne 19-20 (Paris: Centre Georges Pompidou, junio 1987), 65.

17 Jorge Luis Borges, "Alfredo Mario Ferreiro, El hombre que se comio un autobús, Montevideo" en Sintesis 6 (Buenos Aires, noviembre de 1927), 405. Ferreiro continuaría preocupado con el maquinismo. En 1932 pronuncia una conferencia en la Universidad de Montevideo sobre "El hombre y la máquina" (Arte y cultura popular. Universidad de Montevideo. Curso de conferencias, abril-noviembre 1932). Ese mismo año y mostrando su curiosidad bastante ecléctica presentó también un "Prólogo para una disertación de Enrique Casaravilla Lemos" y "Un poco de etopeya y noticia bibliográfica en torno de Israel Zeitlin” el boedista argentino César Tiempo.

18 Borges, 406. 
versos, la calle "chillona, molestada de prisas y ajetreos", que le censura a Maples Arce. ${ }^{10}$ A Borges le perturba en Ferreiro la captación de la violencia de la vanguardia, entendida como intervencionismo en los circuitos convencionales. Más allá de la palabra a flor de labios románticos y modernistas, los escritores vanguardistas anticipan el discurso carismático de la industria cultural. Si Ferreiro se come el ómnibus, Mário de Andrade se traga la radio. ${ }^{20}$ Borges en cambio desconfía que, al captar la violencia de la vanguardia, estos escritores acaben interiorizándola y violen el vigor constructivo del texto. Los futuristas son el modelo más acabado de ese proceso. Para ellos el texto es nada y la performance, todo. De ahí que su poesía sea una poesía para ser recitada y suponga un público al que poder chocar. Es por eso que Borges observa que:

Ferreiro hombre no es menos diablo que Ferreiro escritor. Así me lo dijo la voz más apasionada de Buenos Aires, una voz a la que deberíamos creerle todo, hasta cuando nos dice versos con cisnes: la voz riquísima en fervor de Wally.

(Se refiere, claro, a "Ta recitadora Wally Zenner", comolallama en el artículo que publica en Martín Fierro por ocasión de la presentación de su Luna de enfrente y de quien prefaciará más tarde el poemario Encuentro en el allá seguro. ${ }^{21}$ )

Lo que Borges no anota, pero está inequívocamente presente en el libro de Ferreiro, es la indiferenciación entre el discurso poético y el de la propaganda.

19 Borges, Inquisiciones (Buenos Aires: Proa, 1925), 121.

${ }^{20}$ Eduardo Simões (pseudónimo de Mário de Andrade), Suplemento Diário de São Paulo

(São Paulo, 11 mayo 1930), 9-11. “O homem que era rádio”.

O autor deste conto nos aclara uma nota final —distinguido com Menção Honrosa no concurso de março, é o sr. Eduardo Simões. Acadêmico de medicina. Autor do livro de versos Colcha de retalhos. Reside nesta capital.

Se trata de un curioso caso de auto-pastiche macunarmico y parodia de los clichés regionalistas y modernistas. Transcribo, a título de ejemplo, el principio de este patchwork estilistico:

No tempo d'antes, quando nāo existia nem sombra de automóvel, trem de ferro, aeroplano, rádio, cinema, zepelim, concursos de lindeza, martinelis, marinetis, piolins, perrepistas, liberais, todos esses inventos de agora havia lá pros cafundós do Judas, bem pra cá de Itapecerica, um tal de Jerome Ladislau fenômeno de M'Boi.

Este héroe de arrabal sucumbe finalmente porque ejerce, avant la lettre, la reproducción mecánica. El narrador, en cambio, discreto, "bacharel", sale premiado en un concurso. ${ }^{21}$ Borges, “La aureola con almuerzo y otras erratas”, Martin Fierro 26 (Buenos Aires, 29 diciembre de 1925) y el prefacio a Encuentro en el allá seguro (Buenos Aires: Viau y Zona, 1931). La atracción de Ferreiro por el recitado no debe haber sido episódica. Mi ejemplar de su segundo libro, Se ruega no dar la mano, poemas profilácticos a base de imágenes esmeriladas, tercer cuaderno de la revista Cartel (Montevideo, 1930) perteneció a Nony Hermelo, a quien Ferreiro dedica el ejemplar con admiración porque "recita los poemas como a mí me gusta ofrlos decir". Registro, al pasar, que el segundo libro de Alfredo Ferreiro debía llamarse Poemas con alcance. Al menos asi lo anuncia al publicar uno de esos textos en La Cruz del Sur 26 (Montevideo, octubre-noviembre 1929). 
En efecto, entre los tantos anuncios que abren y cierran ese libro, un aviso del automóvil Ford se superpone, en relación de rasura palimpsestuosa, con el poema de la página 31. De hecho Ferreiro se vale, en esa ocasión, del procedimiento con que justifica, ante sus lectores-pasajeros, el congestionamiento de dos poemas por hoja: "producir un tránsito continuo, vertiginoso y variado, dentro del volumen". Si el efecto arbitrario de artificio, reivindicado por toda vanguardia, se constituye en torno de la actitud entre heroica y patética de rechazo a la mercantilización, vemos cómo en Ferreiro ya se insinúa un cinismo sin prejuicios que, al contrario, reivindica el nuevo canon como mercancía. Si la intención forma la obra, vale registrar que Ferreiro sueña con el mercado para, acaparando la potencia de formar, producir un modelo discursivo intertextual. No es menos interesante observar que, mediante esa operación, Ferreiro suspende también la separación entre teoría e ideología, de tal modo que, cuando nos informa que por el precio de uno tendremos derechoa dos viajes, admite en consecuencia el carácter poroso y precario de su texto, idea que se insinúa en el siguiente itinerario:

Este autobús expide combinaciones, sin alterar los precios del pasaje, para las siguientes líneas de reciente construcción:

\author{
Gervasio Guillot Muñoz-Misaine sur l'estuaire \\ Ramon-Pombo \\ Nicolas Olivari-La musa de la mala pata \\ Jules Supervielle-L'homme de la Pampa \\ Oliverio Girondo-Veinte poemas, etcetera \\ Blaise Cendrars-Moravagine \\ Jorge Luis Borges-El tamaño de mi esperanza \\ Jean Cassou-Eloge de la folie \\ Enrique Bustamante y Ballivian-Antipoemas \\ Paul Morand-Poemes \\ Andre Breton et Philippe Soupault-Les champs magnétiques \\ Raul González Tuñón-El violín del diablo \\ Le Corbusier-Urbanisme \\ Luis Cardoza y Aragon-Luna Park.
}

Noes sólo la ciudad que puede ser atravesada, visitada, por calles y pasajes. El texto también respira por estos canales que constituyen la red simbólica ultraísta. La vía abierta, el arco mundial del horizonte, como diría Saralegui.

Por la vía de una ideología maquinística, Ferreiro nos brinda una reflexión sobre la obra, un arte sobre el arte, potenciado e hipertextual. En cuanto teoría del texto de ruptura, el itinerario y las combinaciones defienden en cambio, con heroísmo bohemio, a la guerra de mercado. Quizás en ese sentido último, de pura ideología, se centre la diferencia programática con Borges. Como anticipándose al arte-pop, Ferreiro aplica su poesía al objetoindustrial, tal como lo hicieron Fortunato Depero, Rodcenko o el mismo Maiacovsky. Claudia Solaris señala ese contacto entre altos y bajos tenores estéticos cuando comenta que: 
non poco il linguaggio futurista ha preso da quello publicitario e ad esso ha restituito, ma proprio nel vivo dell'arte pubblicitaria il futurismo ha potuto operare nella convinzione de aboline il diaframma che abitualmente separava e separa l'arte delle'arte applicata, per praticare cosl un intervento creativo "alto" nel quotidiano sociale, inteso come il più adatto e congeniale all'universo della comunicazione della società di massa. ${ }^{22}$

Es justamente de este linaje, de un arte "al servicio de", que Borges desconfía. Su sospecha se manifiesta en lo que podríamos llamar el discurso de la manía. Borges cree que el libro de Ferreiro es un libro de eufórica alegría y de poca o ninguna felicidad:

Yo creo interesarme mucho en la felicidad y muchísimo menos en la alegría, ya que soy poseedor frecuente de esta última y no de la primera. Esta mínima salvedad personal no es para desentenderme de los aciertos que hay en El hombre que se comio un autobris; es una confesión de distancia.

¿Por qué la felicidad y no la alegría? En una página de La vida literaria, el viejo Anatole France recuerda que, para los latinos, no había diferencia entre la alegría de los hombres y la abundancia de los campos. Para las dos experiencias la misma palabra, laetus. No es la campaña ubérrima sino los márgenes urbanos que lo seducen a Borges. Del mismo modo, es la felicidad civilizada y no la alegría primitiva la que lo mueve. Es lo bello y no lo asombroso lo que lo atrae en Silva Valdés. Diríamos, atando cabos con las reservas antiperformáticas del futurismo: es la ley y no el acto lo que constituye el texto. Sólo que para Borges esa ley es una ley secreta que en ningún texto se concreta y que puede llevarnos a dos concepciones falsamente opuestas: todo se adapta a la ley (luego, no hay libertad); no existe más ley (reina la anarquía). Los textos de Borges nos muestran que la primera conclusión nos conduce a la segunda. Borges se inclina hacia la ley porque defiende la traición. Sabe, como dice Hans M. Enzensberger, que quien no quiera pasar por traidor debe traicionar lo antes

${ }^{22}$ Claudia Solaris, "Il futurismo ela pubblicità" enAlfabeta, 95. El “Poema desencuadernado del perfecto librero" o el "Soneto a la mayor gloria de S. M. Francisco I, Emperador del Café", dos de los avisos del libro de Ferreiro aún cuando se apliquen a comercios bohemios como la Librería del Correo o el Café Tupinambá, no dejan de mostrar una atraccion por el cartel como soporte semítico de la modernización. Es justamente ése el nombre que Ferreiro y Sigüenza darán a su revista: Cartel. En cuanto a las relaciones entre futurismo y publicidad, recuérdese, todavía, el artículo de Lamberti Sorrentino, "Fortunato Depero se divierte" (Martin Fierro 41, 28 de mayo 1927), donde se afirma que sus creaciones dejan a los vanguardistas de buen gusto indiferentes. Para la recepción martinfierrista del futurismo, conviene consultar los números 29-30 (8 junio) y 30-31 (8 julio 1926) de Martin Fierro, contemporáneos de la visita de Marinetti al Plata, así como el último número de la revista, el del 15 de noviembre del 27 , cuando se publica un artículo sobre Boccioni y el porvenir de la plástica del padre del futurismo. 
posible aquello que antes veneraba. ${ }^{23}$ La hibridización de procedimientos constructivos se pauta siempre en su escritura por un principio mayor: la autorreflexividad de la obra, el extrañamiento de las normas dominantes. Veamos un ejemplo. Si en Inquisiciones Borges puede todavía articular las dicciones de Ipuche o Silva Valdes con la lírica andaluza, en su madurez, verá en ese cruce un dato peligroso: un abandono de la traición fundante, una reconversión a la ley, una inconsecuente manifestación de alegría. Detengámonos en los detalles.

En marzo de 1939, Borges comenta "Los romances de Fernán Silva Valdés" ${ }^{24}$ Vale la pena transcribir el económico arranque de su argumentación:

Empiezo, ordine geometrico, por dos inofensivos axiomas:

a) La poesía criolla procede de la española.

b) La poesía criolla difiere de la española.

Silva Valdés - a juzgar por el Romancero del Sur- ha deducido que el primero anula el segundo. Se ha figurado que en el mismo poema (a veces en la misma estrofa) pueden impunemente convivir la voz de Federico García Lorca y la de Martín Fierro. Ha sembrado de torpes hispanismos sus versos criollos. Escribe, por ejemplo:
Los tres hermanos Valiente,
Los tres a la misma hora,
Murieron el mismo día,
Naciendo para la gloria.
Atados a su destino
Coma por la misma soga
Rodaron hacia la muerte
Juntos como boleadoras ...
Los tres hermanos Valiente,
Los tres a la misma hora.

Al haber burlado la ley que supo atacar en Agua del Tiempo, su primer y memorable libro, traición que se da por obediencia servil a lo vago, a lo arcaico y a lo hispánico, Silva Valdés debe ser castigado. Su cruza hispano-cimarrona no puede correr impunemente. Como el gaucho no es en su obra un hombre concebible sino mera ocasión de metáforas y nostalgia -metáforas vistosas, nostalgia veraz-la palabra pierde peso. Nadie la respalda; no hay poder que sostenga esa ley. Por eso, "los libros de Fernán Silva Valdés adolecen de muerte ${ }^{25}$

\footnotetext{
${ }^{23}$ Hans Magnus Enzensberger, "Sobre una teoría de la traición" en Politica y delito. Trad. L. Sala (Barcelona: Seix Barral, 1966), 295-332.

${ }^{24}$ Jorge Luis Borges, "Los romances de Fernán Silva Valdés”. Sur 54 (Buenos Aires, marzo 1939), 70.

${ }^{25}$ Borges, Sur 54, 72.
} 
No era lo que Borges pensaba en 1927. Por ese entonces Silva Valdés era la norma de la anti-norma. Analizando un libro del ya citado Juan Carlos Welker, Chilcas ..., apunta:

Fernán Silva Valdés y un espejo curvo lo causaron a Welker. Fue una imprudencia facilísima de Fernán: arribó a nuestro Buenos Aires, le presentaron ritualmente el Paseo de Julio, y al curiosear un Salón de Novedades en la Recova se le atravesó un espejo caricaturista, de esos que nos difaman. Fernán con azorados quevedos, se miró en él y Welker nació del impertinente cristal, con Chilcas y todo.

Chilcas es una reducción de lo absurdo de Agua del tiempo, es un surtido de parodias de buena fe. ${ }^{26}$

Que a Alfredo Ferreiro le guste la realidad, que Silva Valdés superponga lo hispánico y lo criollo o que Juan Carlos Welker reduzca a la nada el modelo criollista son tres manifestaciones paralelas y complementarias de un mismo fenómeno: afirmación de la norma imperante, abdicación de la experiencia desautomatizadora, trivialización del gusto. Sin deformación, sin extrañamiento, sin originalidad no hay obra. Sin traición no hay ley.

\section{PROCEDENCIA, DIFERENCIA}

Si volvemos al silogismo del que arranca el debate con Silva Valdés quizás podamos establecer otras correlaciones entre el pensamiento crítico de Borges y las realizaciones ultraístas. Decía el autor de Ficciones que lo criollo procede de lo ibérico y que al mismo tiempo, lo criollo difiere de lo ibérico. Vale decir, la procedencia, el linaje, la tradición se dan, justamente, en condición de diferencia y no de identidad, a nivel de deslinde y no de fusión, en valor de ruptura y no de continuidad. Al entender lo moderno como efecto de cruces heterogéneos, Borges trata de superar lo material, lo contingente, lo nacional - lo dadobaraja, superpone y mezcla los datos. Oscila asi entre pasado y presente, entre palabra y pensamiento, entre lenguaje y conciencia. En una defensa tardía de Ipuche, explicita su teoría de la ley de la traición. Escribe entonces que:

lo gauchesco es una función de la nostalgia o un simulacro laborioso y piadoso; quedan determinadas formas, registradas por Ascasubi o por José Hernández, pero no el espíritu que las movio. En Pedro Leandro Ipuche (como en Güiraldes) se da el caso contrario; no están las formas tradicionales, hoy rígidas, y sí la inmediata experiencia. Su léxico no es el de los gauchescos y las historias referidas por él no se ajustan estrictamente a esa tradición. En un lenguaje un tanto fastuoso y heterogéneo recuerda apenas, magnificándolas o tocándolas de ternura, cosas de la tierra oriental. ${ }^{27}$

\footnotetext{
${ }^{26}$ Borges, "Chilcas ... Juan Carlos Welker. Montevideo" en Sintesis 5 (Buenos Aires, octubre 1927).

${ }^{27}$ Borges, "Pedro Leandro Ipuche" en Ficción 5 (Buenos Aires, enero-febrero 1957), 166.
} 
A la norma dominante se responde con la forma emergente, a lo homogéneo con lo heterogéneo. Los cruces son siempre saltos en calidad, cambios de función. Adherir a la procedencia es para Borges aceptar un simulacro de experiencia, hipostasiar la identidad.

Es el momento entonces de confrontar esta concepción del texto y de lo moderno con la que los futuristas $-\mathrm{y}$, en consecuencia, los ultraístas al estilo marinettiano de Ferreiro- podian presentar. Tomemos, por ejemplo, las observaciones del ya citado Anton Giulio Bragaglia en su libro Sottopalco. En ese volumen de ensayos sobre el teatro, el director del grupo de los Independientes de Roma abre su reflexión sobre el género criollo observando que Don Pepe Podestá, italiano de Uruguay, es el fundador del verdadero teatro argentino y justifica esa aparente paradoja cuasi-borgeana argumentando (y cito por la traducción que realizó el líder del modernismo teatral brasileño, Alvaro Moreyra): "sem nacionalismo maníaco, pode-se reconhecer que no meio dessas imitações - se refiere a las contribuciones francesas o españolas-, a única influência sã —que permitiu ao teatro argentino, apesar de todas as pressões, encontrar um caminho próprio e caracteres originais-foi a do teatroitaliano". ${ }^{28}$ Bragaglia sabe que ese tipo de representaciones connotaba barbarie y nunca era visto como teatro de anti-norma, fuertemente original, y que, paralelamente, el teatro rioplatense "em vez de desenvolver em forma nobre o drama gauchesco

${ }^{28}$ Anton Giulio Bragaglia,Fora de cena (Sottopalco). Série de ensaios sobre teatro. Trad. Alvaro Moreyra ( Rio de Janeiro: Vecchi, 1941), 134-5. Anton Giulio Bragaglia (18901960) fue escenógrafo y director de cine y teatro, autor de La maschera mobile (1926), Del teatro teatrale ossia del teatro (1929), Il teatro della Revoluzione (1929, Scultura viviente (1928), Il film sonoro (1929), Evoluzione del mimo (1930); dirigio también algunas publicaciones como Chronache d'Attualità, La Ruota, Bolletino della Casa d'Arte Bragaglia y el Index rerum vivarum que prohibitorum. Mario Verdone puntualiza que "Bragaglia ospito al Teatro degli Independenti tutti i drammaturghi d'avanguardia, diventandone una specie di 'pontifice massimo' ed accogliendo con i futuristi anche opere surrealiste, expressioniste, dada, d'ogni paese" ("Gli 'autori' del teatro futurista" en Alfabeta, op. cit., p. 79). Pontus Hulten, en su monumental Futurismo e futurismi (Milano: Bompiani, 1986), reproduce algunas de las experiencias de fotodinámicas, expuestas en 1912 en la sala Picchetti de Roma, o los retratos de Prampolini y Archipenko. Entre diciembre de 1930 y abril del 31, Bragaglia fue el corresponsal italiano de la revista brasileña Forma, revista de arquitectura, ingeniería y artes plásticas, dirigida en Rio por Alejandro Baldassini. (Además de la sucursal en el 101 de la via Piemonte, Forma contaba con representantes no menos ilustres: Le Corbusier en Francia, Warchavchik en S. Paulo y Julio J. Casal en Uruguay.) De las andanzas americanas de Bragaglia, sabemos, por información de Décio de Almeida Prado, que el director italiano trajo a São Paulo en 1937 a la compañía Laura Adami-Renzo Ricci para representar, entre otras obras, Il ragno de Sem Binelli. Años más tarde, Bragaglia reaparece como cronista teatral europeo de la revista de Paulo Duarte, Anhembi (1950-1962). 
se deixou provincianamente seduzir pelas cocottes dos grands boulevards". Y esto tanto más le espanta cuanto ve que el Teatro de Circo era el espectáculo latinoamericano más interesante, en sintonía internacionalista con los trabajos de Max Reinhardt en el Grosses Circus Schauspielhaus (Das Mirabel, Danton) o podríamos agregar, con Maiacovsky (en Baños, "con circo y fuegos de artificio", Campeonato de la lucha mundial de clases, representado en el Circo de Moscú, o Misterio bufo, hecho también en un circo, durante el III Congreso de la Internacional Comunista, en el 21). En el Juan Moreira de Podestá, en la adaptación del Martín Fierro de Elias Regules o en espectáculos anteriores, Bragaglia observa que los cómicos traen a la escena el caballo y con esa operación "crean un género", que no es otra cosa que cine avant la lettre: "o teatro de massas, de fundo político alegórico, usa os mesmos ingredientes porque usa o campo aberto e põe os cavalos em primeiro plano". La función del teatro europeo de vanguardia noera diferente, en su opinión, de los objetivos perseguidos por el género chico criollo. En una típica lectura vanguardista, retoma la oposición entre desautomatización y kitsch, recalcandoque el teatroexperimental se define como el producto sofisticado de una élite de artistas admiradora de la alta tradición popular y no de la corrupta tradición contemporánea. ${ }^{29}$

Bragaglia (el futurismo) corta la continuidad con la tradición y busca negar lo narrativo del arte. Su épica puede pasar,incluso, por la recuperación nacional (italiana) de un teatro ultramarino que, en lo que tiene de arcaico, señala alternativas posibles para la vanguardia europea. En otras palabras, su proyecto espasmódico de renovación niega la memoria con vehemencia para poder afirmar el arte como utopía. Borges, en cambio, entiende que la memoria estructura la realidad tanto en los restos, que funcionan como soporte de la reconstrucción retrospectiva, como en los cruces de tradiciones disímiles.

Para Borges sólo existen los textos, para Bragaglia, los gestos. Lo curioso de las experiencias de Bragaglia — pienso sobretodo en las fotodinámicas y en su interés por la trayectoria como síntesis del gesto y vertiginosa expresión lírica de la praxis - aunque apuestan a la desmaterialización ( $\mathrm{y}$ aquí entran sus lecturas de Bergson y William James) alcanzan la idealización por la vía de movimiento. Desplazamiento fotográfico, espejos cóncavos y convexos, prismas en el objetivo, descomposición y simultaneidad, aún cuando pretendan analizar el movimiento, no dejan de mostrar la presencia de lo totémico, que Bragaglia interpreta de modo espiritista y esotérico. ${ }^{30} \mathrm{En}$ todo caso, es la sobrevida de lo viejo en lo nuevo, tensión que reencontramos en los ultraístas. Cuando consideramos a los poetas uruguayos del 20 en su conjunto, podemos ver cómo su estética trató, a vecesinfructuosamente, de equilibrarse entre dos concepciones

${ }^{29}$ Anton Giulio Bragaglia, op. cit., 151.

${ }^{30}$ En 1913, Bragaglia publica en la revista Humanistas un artículo sobre el tema "I fantasmi dei vivi e dei morti", donde resuelve la angustia de lo siniestro de forma espiritista. Mario Verdone, "Fotografia futurista" en Alfabeta, op. cit., 93. 
antagónicas de lo moderno-los textos, los gestos. No es gratuito, entonces que, vista de la óptica del 45 , la obra de estos autores mostrase su compromiso con un cierto modo oficial de formar, al tratar de conciliar irreverencia y nativismo. ${ }^{31}$ Silva Valdés lo explicita en una encuesta de La Cruz del Sur:

Creo que el modernismo hay que encararlo cruzándolo con el nativismo. Uno sin el otro decaerán; apoyándose mutuamente, no. Nativismo sin renovación, sin antena receptora de los nuevos modos de sentir y de expresarse sería caer en el error de nuestro viejo criollismo que siempre le atraveś el pingo a todo lo nuevo. Al arte moderno hay que cruzarlo con lo típico para fortalecerlo, atarlo a la tierra no con cabresto: con una raiz. $Y$ tendremos un modernismo participando de lo nuestro y por ende, un nativismo evolucionado y en evolución, que no reniegue del presente y si es posible, que se sobre para mostrar la pasta del porvenir. ${ }^{32}$

El cruce entre criollismo y modernismo debe ser superpesto al que Ferreiro nos propone: el poema como máquina de producir emociones. Vale decir: el automóvil es un poema y el poema, auto-móvil, autonomización de lo estético en clave intertextual. No obstante, el examen de la literatura ultraísta uruguaya nos devuelve un concepto de modernidad escindido: de un lado el poema; del otro, la máquina. Junto al vértigo maníaco de la transformación, la pachorra lastimera rural. Adelante, la máquina, el tren, el automóvil, el avión, en otras palabras, la proas del puerto (tanto como la ciudad internacionalizada, el puerto es la bisagra por donde lo uno deviene lo otro). Atrás, el aljibe, el molino, el parral, el árbol taciturno, la sombrilla del ombú. Si el futurismo quiere cortar la continuidad con la historia, el ultraísmo teme que ese corte instaure la pérdida irreparable de la lógica y la conciencia, de ahí que conserve en su formación ciertos elementos de verismo que le dan sentido de continuidad y permanencia. La subsistencia de una verosimilitud convencionalizada exacerba, pues, la oposición entre la calma (el pasado, el campo) y el movimiento(lo actual, lo urbano), que se traduce, a su vez, en una baja tensión escrituraria: la de un lenguaje que sitúa la identidad en la semejanza, nunca en la diferencia. Por medio de esa fractura entre intención y acto, el ultraísmo idealiza el pasado y actúa lo tradicional colectivo sin criticar la contingencia concreta. Abdica, con

31 "Para nosotros, venidos al horizonte de la literatura después del 40, tres estilos poéticos, si no más, habían quedado abroquelados en la casa de la cultura oficial: [...] el hermetismo devenido precioso; y más atrás el ultrásmo lúcido con sus ribetes nativistas [... y ...] e] erotismo fresco riente, coqueto de Juana de Ibarabourou”, señala Ángel Rama en el prólogo a Los mejores poemas de Juana de Ibarbourou (Montevideo, Arca, 1968), 6. Idéntica es la posición de Ida Vitale en "Los poetas de veinte" (Captulo Oriental. La Historia de la Literatura Uruguaya, 19, Ediciones de la Banda Oriental, 1987).

32 "Contestado a la encuesta de La Cruz del Sur". La Cruz del Sur 18 (julio-agosto 1927), 4, Hugo J. Verani, Las vanguardias literarias en Hispanoamérica (Roma: Bulzoni, 1986), $303-4$. 
esa operación, de concebir lo moderno como lo problemático, y abandona, en consecuencia, la idea de la crisis como un valor.

\section{GESTOS, TEXTOS}

As principais produções do Uruguai são: Lautréamont, Laforgue, Supervielle. O Uruguai conta tres habitantes: Lautréamont, Laforgue e Supervielle, que formam um governo colegial.

Os outros habitantes acham-se exiliados no Brasil visto não se darem nem com Lautréamont, nem com Laforgue nem com Supervielle. Murilo Mendes

Es sabido que los treinta y tres orientales son el conde de Lautréamont y Julio Laforgue. Jorge Luis Borges

La tarea de desmaterialización de la cultura emprendida por el ultraísmo quedó, muchas veces, a mitad de camino. En la respuesta a la indagación de Martín Fierro si existía un meridiano intelectual pasando por Madrid, Idelfonso Pereda Valdés subraya que, de existir esa línea orientadora, no pasaría por Madrid sino por Buenos Aires y lo hace con un argumento totalmente modernizador: a los escritores americanos les interesa conquistar un público americano. O sea que lo moderno viene nuevamente aparejado a lo nacional, la ruptura a la tradición:

estamos construyendo nuestro arte propio: azteca, inkaiko, o criollo puro [sic] y nos violentan los gestos protectores de los que pretenden llamarse tutores nuestros. ${ }^{33}$

\footnotetext{
${ }^{39}$ Ildefonso Pereda Valdés, "Madrid, meridiano". Martín Fierro 42 (junio-julio, 1927). La idea de un criollo-puro como sistema supranacional equiparable a las otras grandes áreas culturales americanas (la azteca, la incaica) muestra cómo Pereda Valdés pretendía equilibrar un mercado regional argentino-uruguayo-brasileño. La intercomunicación entre estas dos ultimas literaturas reconoce algunos antecedentes dignos de nota. Los hay de carácter oficialmente panamericanistas, como la serie de artículos "La literatura uruguaya: 1757-1917" que Ventura Gancía Calderon y Hugo D. Barbagelata publican en la Revista Americana de Rio de Janeiro, de noviembre de 1918 a setiembre del 19. Es también del 19 la tesis académica del Prof. Brenno Arruda, presentada a la cátedra de Español del Colegio Dom Pedro II: APoesia Uruguaia. Los hay de interés especificamente estético, como el artículo de José Veríssimo sobre Carlos Reyles (Homens e cousas estrangeiras, la série) o el de Themudo Lessa sobre Angel Falco (América Latina 2, setiembre 1919). Llega a haber contactos modernos y de masa como el número que la Revista do Globo dedica a las letras del Uruguay, con un artículo de Luz Vergara (17, Porto Alegre, 13 setiembre 1930). Entre los escritores modernistas el interés no es menor. Dijimos que el gusto de Manuel Bandeira parece un poco convencional (Oswald de Andrade dirá, en una entrevista a Diretrizes en 1940, que lo consideraba a Bandeira un gran poeta pero un crítico flojo y poco orientado, solo superior a Tristão Athayde, lo que, en boca de Oswald, no era exactamente elogio, como se confirmará más tarde, en 1953, cuando dirá que "Bandeira é um chato. Fez seis poemas muito bons e vem cavalgando todo ese tempo").
} 
Podemos entonces leer la militancia intelectual de Pereda Valdés como ensayo de crear un público. A los libros se suceden los artículos en periódicos vanguardistas. Basta, a título de ejemplo, con rehacer la trayectoria de un par de años de proselitismo de vanguardia. En enero de 1927, Pereda publica en Martín Fierro ( $\mathrm{n}^{\mathrm{9}} 37$ ) un artículo, "Film", suerte de greguerías críticas al estilo del Parnaso satírico de esa revista donde, entre otras torquemadas trata a Zorrilla de San Martín de Bécquer disfrazado de charrúa, conquistando la Banda Oriental (o sea que le redefine los meridianos). En abril y en el número 40, comenta las "Páginas Muertas de Eduardo Wilde"; en el número siguiente, el antologista de la moderna literatura uruguaya, consciente de la doble limitación de esa obra (por antológica y por moderna) trata de sacar del anonimato (tal vez previendo el que le esperaba) al autor de la Anthologie de la Nouvelle Poésie Française, declarando que sólo podía tratarse de Breton: las líneas sobre Jarry son idénticas a las de Les Pas perdus. En el número 42, de julio, presenta unas "Anotaciones marginales a un libro mal premiado" de José Gabriel y en el número de agosto reseña "La exposición de pintura uruguaya" de Amigos del Arte.

La persecución de un heterogéneo público criollo-puro lo lleva, tres meses más tarde, a las páginas de la revista Verde de Cataguazes, donde saluda "A Germana Bittencourt" (cantante lírica brasileña casada con el poeta martinfierrista Pedro Juan Vignale) y a través de ella a "Bandeira y los amigos que estrecharán mi mano", el mismo Bandeira que divulga su obra en la Revista do Brasil ${ }^{34}$ En el quinto número de Verde, abriendo 1928, pequeñas noticias de la redacción dan cuenta de que Pereda Valdés pronunció un par de conferencias en la Universidad y en el Curso Vigil sobre poesía brasileña o que proyecta para mediados de año una exposición de Xul Solar, Norah Borges y Maria Clemencia en Montevideo. Finalmente, en el primer número de la segunda fase, Verde, en mayo de 1929, Pereda Valdés hace un "Elogio a Voronoff". Los modernistas mineiros ven a Pereda Valdés como un vanguardista contenido y sutil. Henrique de Resende, director de Verde, anota que:

Ildefonso, muito mais normal e equilibrado, em comparação com os modernistas brasileiros, não deixa por isso de ser encantador na sua modernidade. Há nos

Sin embargo, Mário de Andrade demuestra haber conocido mejor a los uruguayos. Libros de Pereda Valdés, Alfredo Mario Ferreiro, Ortiz Saralegui, Sarah Bollo, Humberto Zarrilli, los Guillot Muñoz y un total de más de treinta autores, así como las revistas de vanguardia (La Cruz del Sur, Izquierda, Vanguardia, Cartel, Renovacion, Delfos, etc.) son prueba fehaciente de un ojo crítico más aguzado. Remito al interesado en los pormenores de esa interrelación a mi libro Na Ilha de Marapatá: Mário de Andrade lê os Hispanoamericanos. Pref. Alfredo Bosi (São Paulo, Hucitec; Brasflia, INL, 1986).

${ }^{34}$ Manuel Bandeira, "Pereda Valdése poesia platense" (1 agosto 1931), incluido por Carlos Drummond de Andrade en Andorinha, andorinha (Rio de Janeiro, Jose Olympio, 1966), 331-333. 
Cinq Poemes Négres, tal como num outro livro seu - La guitarra de los negrostoda a relembrança dos tempos bárbaros da escravatura. É um livro evocativo das senzalas, com os seus brocotós e os seus gingos de sensualidade africana. A brutalidade do comércio e consequente pega dos negros. O sofrimento inaudito das travessias. $O$ trabalho forçado nas lavouras. $O$ chicote trançado dos verdugos. A pena é que Ildefonso tenha parado al. $O$ tema bem que merece maior assuntação. Mas, na verdade, tudo o que o poeta assuntou ficou bem assuntado. Com felicidade de pensamento e técnica. ${ }^{96}$

Ese mismo equilibrio es objeto de elogio en la reseña que uno de los grandes poetas de Minas, Emnlio Moura, le dedica en el último número de A Revista ${ }^{36}$ Ese profesional de la interrogación, como lo definió Drummond de Andrade, discrepa sin embargo de Pereda Valdés en su teoría de lo moderno, centrada menos en las imágenes y más en la búsqueda atónita:

É curioso notar o que diz esse poeta, falando do "modernismo". "Asi el modernismo se diferencia del romantismo más que nada en las imágenes". Antes já havia dito: 'mejor dicho, es lo único (a natureza das imagens) que caracteriza y diferencia a los movimientos literarios'. Até certo ponto, de acordo. Mas pensar dessa maneira é ver o problema no que ele possui de exterior. As imagens são um recurso da inteligência, e nunca a expresão exata do que nós possuímos de interior e de diferenciado, a própria esséncia da nossa personalidade. Querer julgar, por exemplo, um poeta como Cocteau pelo capricho das suas imagens ou pela cintilação de seu verbo, é ficar muito longe da complexidade diabólica desse espirito perturbador. É verdade que se poderia fazer um estudo dos movimentos literários, valendo-se muito desse ponto de vista. Podia ser até curioso. Mas isso seria apenas focalizar uma manifestação diferenciadora. Por ou tro lado surgiria logo uma ou tra dificuldade. As imagens vivem do capricho do nosso momento criador e emotivo e trazem um pouco da leviandade desse capricho. Que diferenca, por exemplo, entre a natureza das imagens na obra de um Giraudoux e na de um Max Jacob! O que faz com que eles sejam modernos é menos a natureza das imagens do que o próprio espirito da obra de cada um deles, é menos a expressão verbal do que a expressão interior. Não podemos, portanto, girar todo o problema do modernismo somente sobre uma de suas faces.

${ }^{35}$ Henrique de Resende, “Cinq poèmes nègres - Ildefonso Pereda Valdés - Cruz del Sur 927 - Buenos Aires”. Verde 4 (Cataguazes, diciembre 1927), 25. Los verdes de Cataguazes no lo descubren; son descubiertos: "Ildefonso Pereda Valdés veio até Verde numa quadrilha. Mas é preciso não confundir: numa quadrilhadança, essa montoeira de gente que foi o gozo ingênuo dos nossos avòs". "Explicação: o Fusco escreveu pro Ildefonso (cônsul). O cônsul escreveu pro Ildefonso (Pereda). E nesse vai-vem o Pereda mandou os troços pro cónsul, e num passo direto, o consul mandou pra Verde os referidos".

${ }^{36}$ Emflio Moura, "El arquero e La casa iluminada . Ildefonso Pereda Valdés. Montevideo". A Revista 3 (Belo Horizonte, enero 1926), 50-52. 
Es por otra parte, lo que también notará Borges, unos meses más tarde, cuando en las páginas de Martín Fierro, analice La guitarra de los negros:

su seriedad joven, sus enviones de entusiasmo, su calmosa incredulidad criolla, su propósito de emparejar lo tradicional con la novedad. Su técnica es muy mil novecientos veintipico y hasta me parece escuchar colazos del creacionismo en alguna estrofa; sus temas son tradicionales. Esa guitarra de los negros que invoca, esa guitarra que dice la elegía de los candombes del ochenta y plañe la ausencia de los tambores, las mascallas y las marimbas, $i$ no es una cosa patética y tradicional, de raíces viejas en el tiempo? ?7 $^{37}$

No obstante, para Borges, es, quizás, justamente por la deuda creacionista, que Pereda Valdés alcanza su mayor valor moderno. Su poesía —nos dice-es autobiográfica y siendo así es, concomitantemente, moderna y compleja, porque su nervio, la imagen, es paradojalmente, por etimologia, simulacro y por ideología, precisión. La imagen es expresión del yo, esa nadería que, sin embargo, es la literatura porque "toda literatura es autobiográfica, finalmente. Todo es poético en cuanto nos confiesa un destino, en cuanto nos da una vislumbre de él".

No siempre las lecturas vanguardistas -martinfierrismo platino y modernismo brasileño- pueden situarse lado a lado. Tomemos un ejemplo de lecturas discordantes: Montevideo y su cerro de Montiel Ballesteros. En noviembre de 1928, Borges y Antonio de Alcântara Machado se ocupan del libro de Montiel.

Alcântara Machado, director de la Revista de Antropofagia de São Paulo, y defensor de la sinceridad afirmativa en el arte, ${ }^{39}$ rescata en ese autor inquieto y apresurado el nervio de esos:

contos sincopados com um pouco de sátira e um pouco de invenção. Pensando bem: mais de invenção do que qualquer outra coisa [...] O conto 20 Blasco Ibáñez é bem característico de sua maneira: nem é propriamente conto nem deixa de o ser.

\footnotetext{
${ }^{37}$ Jorge Lu is Borges, "Nota bibliográfica al libro de Ildefonso Pereda Valdés". Martín Fierro 30-31 (8 julio 1926).

${ }^{38}$ En "La simulación de la imagen", ensayo de El idioma de los argentinos, Borges ya nos dice que la imagen es "la forma de la espada", rastro, huella o incisión que, siendo presente, permite reconstruir el pasado: "imago vale por simulacro, por aparecido, por efigie, por forma, a veces por vaina (que es la apariencia de la hoja de acero que está en acecho en ella aunque también por eco - vocalis imago-y por la concepción de una cosa". Si en "La nadería de la personalidad" (de Inquisiciones) nos repite que el yo no existe, en "Profesión de fe literaria" (de El tamaño de mi esperanza) cifra la literatura en el yo, un yo desmaterializado.

${ }^{39}$ Véase su columna "Saxofone e cavaquinho" del Jornal do Comércio de São Paulo, en especial la de 20 noviembre 1926: "Uma qualidade moderna" en Obras I: Prosa preparatoria \& Cavaquinho e saxofone (Río de Janeiro: Civilização Brasileira/INL, 1983), 200-4.
} 
Tal vez refrenado por ver en Montevideo y su cerro algo muy próximo de lo que él mismo intenta en Bras Bexiga e Barra Funda, Alcântara Machado duda en reconocerle mérito artístico por descubrir la significación de cosas insignificantes, o captar la efímera precariedad que define el trabajo periodístico y la misma modernidad. ¿Es acaso un elogio decir que si Montiel Ballesteros no es periodista debía serlo porque tiene las cualidades del cronista - "escreve com extraordinária facilidade, põe logo o negócio em pratos limpos, parece ser um vivido"? ${ }^{40}$ Estamos, sin duda, frente a un elogio de la literatura-gesto. En la vereda de enfrente, ese mismo mes, Borges también reseñaba Montevideo y su cerro, con restricciones previsibles dada su teoría de la traición anticonvencional. Transcribo, pues, el texto donde ya anuncia una idea central en su estética (y muy valeriana), la de la convencionalidad transitoria de los signos:

Las metáforas se vuelven palabras. Yo ignoro si el todavía misterioso lenguaje es una convención, pero es de fácil observación que propende a serlo y que los lugares comunes de ahora son el resto insipido de las audacias expresivas de ayer. Admitida ya una expresión, su felicidad o inadecuación primordiales no nos importan: se ha condensado en palabra, es decir, en símbolo de curso legal que todos aceptan y cuya inspección es inútil. Leer, verbigracia, blanca como la nieve, es ocupación descansada, porque la intención elogiosa - la primordialse sobre (o sub) entiende, y no preciso ni figurarme la nieve, que en estas no glaciales repúblicas, tampoco ha sido vista por el escritor que para encarecimiento de la blancura, suele invisiblemente decirla. En cambio, el posible futuro lugar común blanco como el hastio no se ha adensado todavía en palabra: es una impertinencia que me distrae, una propuesta conexión de representaciones

\footnotetext{
${ }^{40}$ Antônio de Alcântara Machado, "Dois poetas e um prosador" en Revista de Antropofagia 7 (São Paulo, noviembre 1928), 4. Conste, además, que el mismo Alcântara Machado ya había reseñado La trompeta de las voces alegres de Nicolás Fusco Sansone en el tercer número antropofágico (julio 1928) y que de ese poeta uruguayo la misma revista había publicado ( $\mathrm{n}^{\circ} 2$, junio 1928) su poema "La gracia del amor puro". Unos meses antes, la dinámica Verde de Cataguazes ya había presentado Fusco Sansone al público brasileño con "El nocturno de los cuerpos anhelantes" ( $n^{0} 5$, enero 1928, 8). En cuanto a la lectura que Alcântara Machado hace del libro de Montiel véase cuán lejos de Borges y cuán cerca de Alfredo Mario Ferreiro se sitúa. En el número 21 de La Cruz del Sur (diciembre del 28), el poeta uruguayo exalta lo que el escritor antropofago elogia y lo que Borges toma con reservas: “'20 Blasco Ibáñez', 'Aventura con siete mujeres y un general', El botín', 'Más allá del feminismo' y '18 y Andes' son relatos de una insuperable modernidad. Montiel deja libre paso al humorista que hay en su espiritu y se divierte tirando los piolines a esa serie de personajes que, grotescos y todo,nos van trayendo a la memoria el recuerdo de tipos conocidos. Y eso prueba la fuerza indiscutible que hay en las estilizaciones de Montiel" [...] "Montiel ha querido hacer un libro a la moderna, y le ha salido - porque tiene inteligencia para mucho más - un aspecto nuevo, -quizá más moderno que lo moderno que se estilaba- del relato movido como viaje de autobús por empredado de cuña". Sobre Montiel Ballesteros, Brito Broca publico "Um interprete da paisagem e do homem do pampa" en Pensamento da América (Rio de Janeiro, 23 marzo 1947).
} 
disimiles que debo examinar y que con toda probabilidad no funciona. Por eso, es más incómoda la equivocación novel que la antigua.

Ambos lenguajes -el de los ya invisibles lugares comunes de ayer y el de los demasiado visibles de mañana-conviven despreocupadamente en este libro de Montiel Ballesteros. Mejor dicho: el segundo ha sido supuesto al usual. Dos lenguajes valen dos almas. Me gusta más la antigua; creo que es la auténtica de Montiel. Sus conatos de alucinación-18\& Andes, Aventura con siete mujeres $y$ un general - son de tropezada lectura. Inversamente, hay cuentos que son cuentos y que logran rescatar, anulándola, la insignificancia trabajosa de los demás. Pienso en Panchito Cortabarría, en La obra. Yo prometo, en señal de paz y perdón, acordarme de este último, cada vez que el nombre de Montiel Ballesteros sea mencionado. Es la relación de un fracaso, de un fracaso propio evidenciado a quienes estaban padeciéndolo sin saberlo, en otra persona y que se sienten confesados en él. Es de invención hermosa. ${ }^{41}$

En Montiel Ballesteros, en Alfredo Ferreiro, en Alcântara Machado está lo moderno a ultranzay, no raramente, la literatura-gesto. En Borges, en cambio, una cierta incomodidad ante esos dos lenguajes, que valen dos almas, nos muestra su concepto de hibridismo substantivo. No puede haber superposición sino injerto, escritura, literatura-texto. La oposición (vanguardista) entre originalidad y trivialización (que aparece aquí y ya lo hiciera en la reseña de Welker) empieza a borrarse para Borges y para la literatura. Entre un enunciadoy otro, que mucho después lo reedita puntualmente, no hay distinción de valor, tan sólo una repetición regular que consolida una convención. ¿Ese yo que no es yo, ese algo que nada es, ese criollo impuro que no siendo tal postula pureza, puede ser original? ¿Puede ser literatura?

En este texto de Borges ya se insinúa una idea consecuente de modernidad. No la que abomina trivialidad sino la que amasa modernidad a partir de lo abyecto. A partir de esta lectura de Borges, se puede concluir un programa de escritura. Si la postulación de cualquier originalidad (textual, nacional) pierde toda pertinencia, es porque lo propio de la literatura es poder ser repetida, retomada, citada o evocada. Excepción hecha de Emílio Moura, los modernistas brasileños ven en los ultraístas de Montevideo el mismo gesto fundante de modernidad. Borges, al contrario, en ellos evoca textos que siendo ajenos le son propios. No sólo se relativiza así la idea de lo nacional sino la misma idea de la comparación, concebida como apareamiento de unidades distintas. Recordemos la discrepancia de Borges con Vicente Rossi en relación a un pretendido idioma común platense:

Rossi nos informa que los argentinos estamos en posesión de un lenguaje propio, de un idioma nacional rioplatense (argentino-uruguayo), y lo prueba señalando la disconformidad de nuestra costumbre con las definiciones de páginas enteras

\footnotetext{
41 Jorge Luis Borges, "Montevideoy su cerro por Montiel Ballesteros". (Montevideo, 1928)" en Sintesis 18 (Buenos Aires, noviembre 1928), 351.
} 
del diccionario oficial. Lo descreo de su hipótesis valerosa, por dos razones. Primero, es curioso que lo tengamos tan callado a ese idioma distinto. Segundo, la disconformidad señalada puede no ser con el corriente idioma español, sino con los chapuceros de la Academia. Sabemos que desbarran infaliblemente, en lo americano, ¿por qué no en lo peninsular, muchas veces?"2

No habiendo comunidad, la única vía de establecer un puente es por el deseo de incomunicar, de extrañar las prácticas convencionales, como recomienda en unas anotaciones sin duda sugeridas por el neo-criollo de Xul Solar. ${ }^{43}$

La cuestión de un meridiano, de una fuente o de un origen no se responde para Borges al modo esencialista de Pereda Valdés. Se responde en los textos. Mejor dicho: ya se había respondido cuando en una colaboración para La Prensa de 1926 postula la existencia de dos clases de traducciones: "una practica la literalidad; la otra, la perífrasis. La primera corresponde a las mentalidades románticas; la segunda a las clásicas”. Y razonando para disminuir el aire de paradoja, agrega:

a las mentalidades clásicas les interesa siempre la obra de arte y nunca el artista. Creerán en la perfección absoluta y la buscarán. Desdeñarán los localismos, las rarezas, las contingencias [...] Inversamente, los románticos no solicitan jamás la obra de arte, solicitan el hombre [...] Esa reverencia del yo, de la irremplazable diferenciación humana que es cualquier yo, justifica la literalidad en las traducciones. ${ }^{44}$

Leyendo a sus compañeros ultraístas de la otra banda, Borges no sólo va madurando su concepción hipertextual de lo literario. Llega también a descubrir la irrelevancia de postular lo uno y lo diverso porque eso equivaldría a aceptar la existencia de una conciencia metafísica que se originaria en lo uno y se desarrollaría en lo otro. Borges ha de preferir, en cambio, las multiplicidades aleatorias que se cruzan y entrecruzan, tejiendo una dicción común.

42 Jorge Luis Borges, "Idioma nacional rioplatense por Vicente Rossi(Folletos lenguaraces, $6)^{n}$ en Sintesis 18, noviembre $1928,361$.

${ }^{43}$ Borges, "El idioma infinito" en El tamaño de mi esperanza (Buenos Aires: Proa, 1926).

44 Y anticipando su teoría pierremenardesca del palimpsesto, remata: "En cuanto a las repetidas versiones de libros famosos que han fatigado y siguen fatigando las prensas, sospecho que su finalidad verdadera es jugar a las variantes y nada más. A veces el traductor aprovecha los descuidos o los idiotismos del texto para verle comparaciones. Este juego bien podria hacerse dentro de una misma literatura. ¿A qué pasar de un idioma a otro?" Es sabido que el Martin Fierro empieza con estas rituales palabras: "Aquí me pongo a cantar al compás de la vigüela". Traduzcamos con prolija literalidad; "En el mismo lugar donde me encuentro, estoy empezando a cantar con guitarra". Y con altisonante perífrasis: "Aquí en la fraternidad de mi guitarra, empiezo a cantar" y armemos luego una documentada polémica para averiguar cuál de las dos versiones es peor. La primera; tan ridícula y cachacienta! es casi literal". Ver "Las dos maneras de traducir" (La Prensa, Buenos Aires, 1 agosto 1926). 